\title{
Assessment and Management of Pain in Patients Sustaining Burns at Emergency Department Kenyatta National Hospital, Kenya: A Descriptive Study
}

\author{
Vihar R. Kotecha ${ }^{1, * \mathbb{D}}$, Nyaim E. Opot ${ }^{2}$ and Ferdinand Nangole ${ }^{2}$ (D) \\ 1 Department of Surgery, Catholic University of Health and Allied Sciences, Mwanza 1464, Tanzania \\ 2 Department of Surgery, University of Nairobi, Nairobi 65001-001, Kenya; elly64ke@gmail.com (N.E.O.); \\ nangole2212@gmail.com (F.N.) \\ * Correspondence: viharkotecha@hotmail.com
}

check for updates

Citation: Kotecha, V.R.; Opot, N.E.; Nangole, F. Assessment and Management of Pain in Patients Sustaining Burns at Emergency Department Kenyatta National Hospital, Kenya: A Descriptive Study. Trauma Care 2022, 2, 79-86. https:// doi.org/10.3390/traumacare2010007

Received: 25 November 2021 Accepted: 24 February 2022 Published: 1 March 2022

Publisher's Note: MDPI stays neutral with regard to jurisdictional claims in published maps and institutional affiliations.

Copyright: (C) 2022 by the authors. Licensee MDPI, Basel, Switzerland. This article is an open access article distributed under the terms and conditions of the Creative Commons Attribution (CC BY) license (https:// creativecommons.org/licenses/by/ $4.0 /)$.

\begin{abstract}
Background: Poorly managed burn pain affects the victim by delayed healing, psychological disturbances, and chronic pain. Burn injuries are the fourth leading cause of injuries worldwide. The incidence of thermal burns in Kenya is 3\%. Pain assessment and control are integral parts of management that a burn victim should be offered. We lack data on pain management in burn patients during setup. Methods: A descriptive study was carried out at the emergency department (ED) of Kenyatta National Hospital. We enrolled patients who sustained thermal burns until a sample 138 patients was reached. Enrollment of patients was done from February to August 2015. The pain level was assessed using a visual analogue scale, and the Lund and Browder chart was used to record the depth and extent of the burn. Data on the type of analgesia prescribed and its route of administration was collected. Data was analyzed using STATA v.11. Results: The median age of the sample was 28 years with a male to female ratio 1.8:1. The majority of the victims (38\%) sustained flame burns. The median total body surface area was $19.5 \%$. Pain assessment was done in $2 \%$ with a visual analogue scale and face pain recognition scale. Mean Visual Analogue score was 7. Analgesia was offered to $96 \%$ of participants, and it was unimodal in the majority, $76.7 \%$, and the preferred drug of choice was morphine. The majority of all burn patients had sustained moderate to major burns. The tools used to assess pain in this hospital were Face Pain Recognition Scale and Visual Analogue Scale; however, pain assessment was done on a meagre $2 \%$ of the sample. Conclusions: A minority of the patients had any sort of pain assessment done at the emergency department. As a result, burn pain was inappropriately managed. There is a need to improve the assessment of burn pain and improve its management by encouraging training of ED burn care providers by burn surgeons and pain therapists.
\end{abstract}

Keywords: pain assessment; thermal burn; visual analogue scale; burn pain management; developing country

\section{Introduction}

Burn injury is a public health problem; globally, they are ascribed as the fourth leading cause of injuries requiring medical attention. In 2004, the worldwide incidence of burns needing medical attention was eleven million [1,2]. In Kenya, the overall incidence of burns has been described to be 3\% [3]. Thermal burns have been a leading etiology for burns in Zimbabwe 98\% [4], Tanzania 96.5\% [5] and Kenya 94-100\% [6,7]. Thermal burns lead to significant tissue injury proportional to the body contact time, the temperature of the insulting substance, age of the patient and the etiology burn, for example, steam, boiling water, or chemicals [6,8].

Patients with burn injury undergo a considerable amount of pain. Pain perception is a subjective feeling, and individualization is necessary for its management [9,10]. Furthermore, the perception of pain has been described to differ with the depth of burns. 
Castana et al., in their study, explained that superficial burns were the most painful ones [11]. It is of utmost importance to assess the level of pain in each patient and gear treatment so as to reduce pain to a minimum if elimination is not possible $[9,10]$.

Burn injury pain has been sub-stratified into background pain, breakthrough pain and procedural pain $[9,12]$. An objective approach to pain assessment and management is necessary to increase comfort, cooperation, and satisfaction. Different pain assessment methods have been described in various pieces of literature [12,13]. The Visual Analog Scale is a numerical scale ranging from $0-10$ in which the victim selects a number reflecting to their level of pain, zero being no pain and 10 being the worst pain ever [14]. The use of VAS has been validated as a sensitive tool for assessing pain in burn victims [14]. Other tools are the face pain recognition scale (FPRS) [15], verbal descriptive scales and more complex multidimensional tools are McGill Pain Questionnaire, Brief Pain Inventory (BPI) and the abbreviated Burn Specific Pain Anxiety Scale (BSPAS) $[10,14,16]$.

A multidisciplinary team approach and multimodal pharmacologic pain management should be utilized for the treatment of burn patients. In pharmacologic management of burn pain, opioids form the cornerstone of treatment. Multimodal pharmacotherapy would really benefit patients with severe burns necessitating admission, as opioids form the cornerstone of multimodal pain management, its addition with a non-steroidal antiinflammatory and or acetaminophen [17] would significantly reduce the pain to nadir levels. Multimodal pain management includes different routes of administering analgesics such as continuous intravenous drip, intravenous injections bolus at the prescribed duration, intramuscular injection, or oral tablets [17]. Anxiety has been shown to catalyze the onset of pain due to anticipation of a dressing or any other procedure. In the American context, the utility of anxiolytics also forms a component of multimodal pain management [17]. Ideally, multimodal pain management should begin at the emergency department (ED), and analgesics should be administered to maintain adequate serum analgesic levels to keep the patient relatively free of pain [9]. Although burn injury pain was described as a significant clinical problem over two decades ago, it has continued to be reported that burn pain remains undertreated [9]. This is of concern because unrelieved pain is thought to contribute to patient discomfort hence poor cooperation, dissatisfaction, delayed healing, and prolonged hospitalization. Furthermore, poor management of pain can contribute to long-term sensory problems like paraesthesia, chronic pain and debilitating psychological conditions like depression and post-traumatic stress disorder [12,18,19]. Within Kenya, depression was noted in $85.5 \%$ of burn patients, and it was statistically associated with prolonged hospital stay [19]. Other long-term consequences include chronic pain, a common problem amongst burn survivors, accounting for $52 \%$ worldwide [9].

This study aimed at assessing the modalities of assessing pain and its management at the emergency department.

\section{Methods}

Descriptive prospective study was carried out at the emergency department (ED) of Kenyatta National Hospital in Nairobi, Kenya. Our sample size was calculated using the Kish and Leslie formula, and sequential enrolment of patients with thermal burns was done for six months from February to August 2015 until a sample size of 138 participants was reached. A data form was used to collect demographic data, etiology of burns, extent of burn, pain assessment practice at ED, and pain score at the ED together with the modality of pain control at ED. Etiology, the extent of burn, was measured using the Lund and Browder chart, and pain was assessed using the visual analogue scale (VAS) as soon as the victim arrived at the doctor's room. Analgesic prescriptions were recorded from the patient records. Patients requiring advanced airway management, those who arrived twenty-four (24) hours post burn, patients with other associated injuries and those who were under 13 years of age were excluded. All data was collected by the principal author and trained research assistants. STATA version 11 (StataCorp LLC, College Station, TX, USA) was used to carry out the data analysis. Chi square was used to determine the association between 
categorical variables. Ethical permission was obtained from UoN-KNH Ethics Research Review Committee.

\section{Results}

This study enrolled 138 participants, the median age was 28 years (IQR 22-34), and $89(65 \%)$ were males, making a male to female ratio of 1.8:1.

The most common etiologies (refer to Figure 1) of thermal burns were flame burns, $49(35.5 \%)$, and scald burns from water, 47 (34\%), scald from other hot liquids, 38 (27.5\%), and $4(3 \%)$ were caused by flammable liquids, e.g., kerosene and petrol.

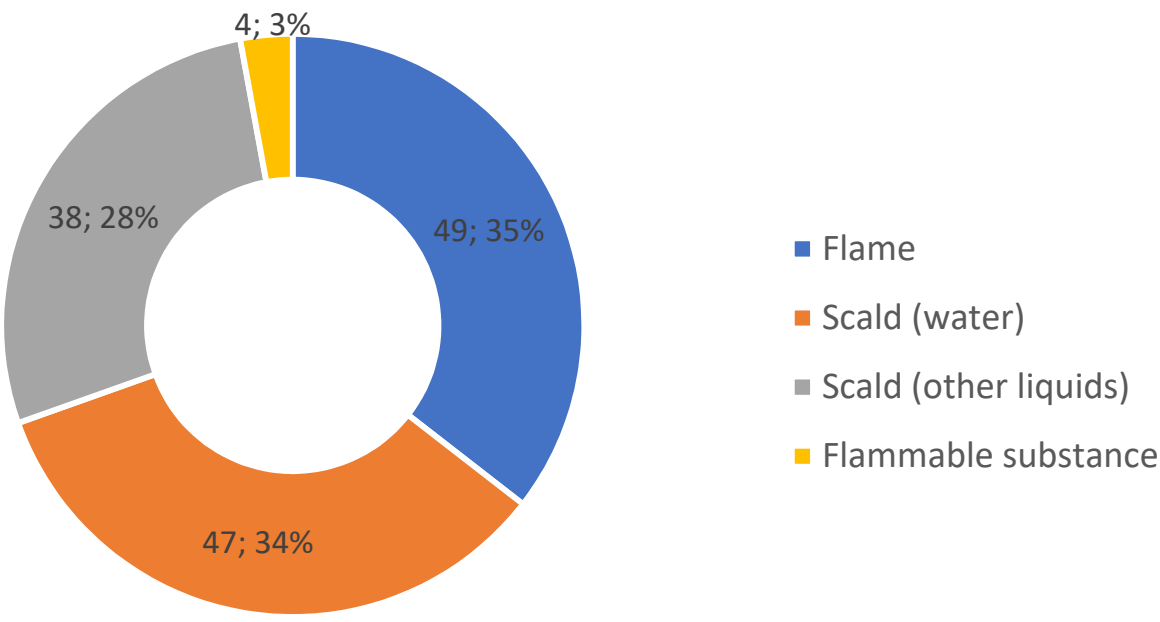

Figure 1. Etiology of thermal burns.

In this study, median total body surface area (TBSA) of burn was 19.5\% (IQR 15-27.5\%). Burn injuries were categorized into minor, moderate and major burns, as seen in Figure 2.

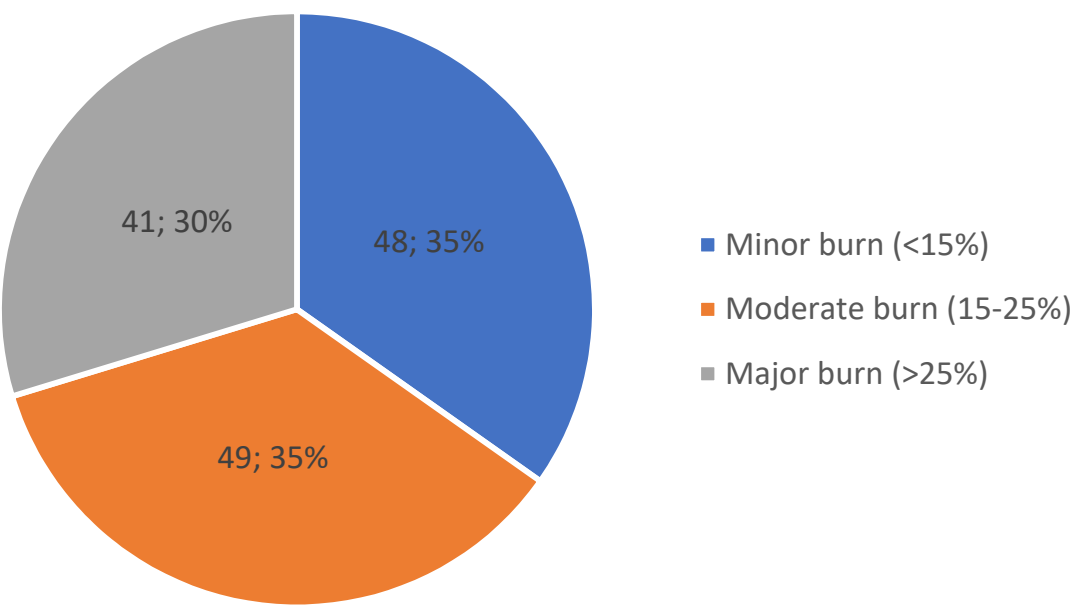

Figure 2. Total body surface area of burn.

At the emergency department, pain assessment was done on a meagre $3(2 \%)$ participants and the tool used was FPRS 2 (67\%) and VAS 1(33\%) (Figure 3). 


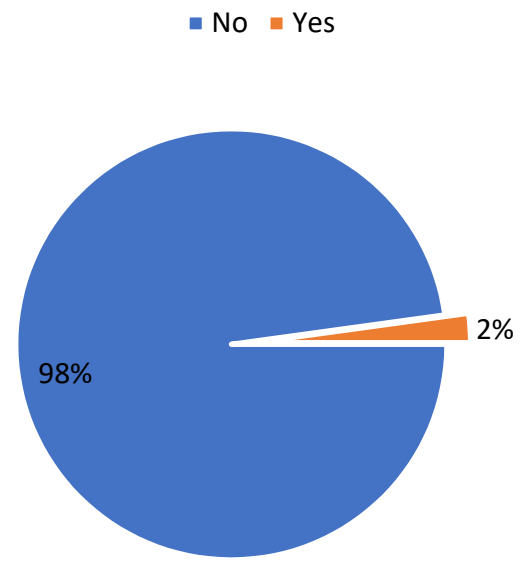

Figure 3. Pain assessment at ED by hospital staff.

We assessed pain in all participants (refer to Table 1), the mean VAS score was 7 (SD 1.4), and Chi-square was used to assess statistical relationship between severity of burn in TBSA and VAS category, $\mathrm{X}^{2}=13.9, p=0.08$.

Table 1. VAS score in relation to TBSA.

\begin{tabular}{ccccc}
\hline \multirow{2}{*}{$\begin{array}{c}\text { Severity of Burns } \\
\text { in TBSA }\end{array}$} & $\begin{array}{c}\text { Moderate Pain } \\
\text { (VAS 4-7) }\end{array}$ & $\begin{array}{c}\text { Severe Pain } \\
\text { (VAS 8-9) }\end{array}$ & $\begin{array}{c}\text { Worst Pain } \\
\text { (VAS 10) }\end{array}$ & Total \\
\hline Minor burn & $31(64.6 \%)$ & $17(35.4 \%)$ & $0(0.0 \%)$ & $48(100 \%)$ \\
Moderate burn & $28(57.1 \%)$ & $21(42.9 \%)$ & $0(0.0 \%)$ & $49(100 \%)$ \\
Major burns & $14(34.2 \%)$ & $22(58.5 \%)$ & $5(7.3 \%)$ & $41(100 \%)$ \\
Total & $73(52.9 \%)$ & $62(44.9 \%)$ & $3(2.2 \%)$ & $138(100 \%)$ \\
\hline
\end{tabular}

There was no correlation between pain score and degree of pain, refer to Figure 4 .

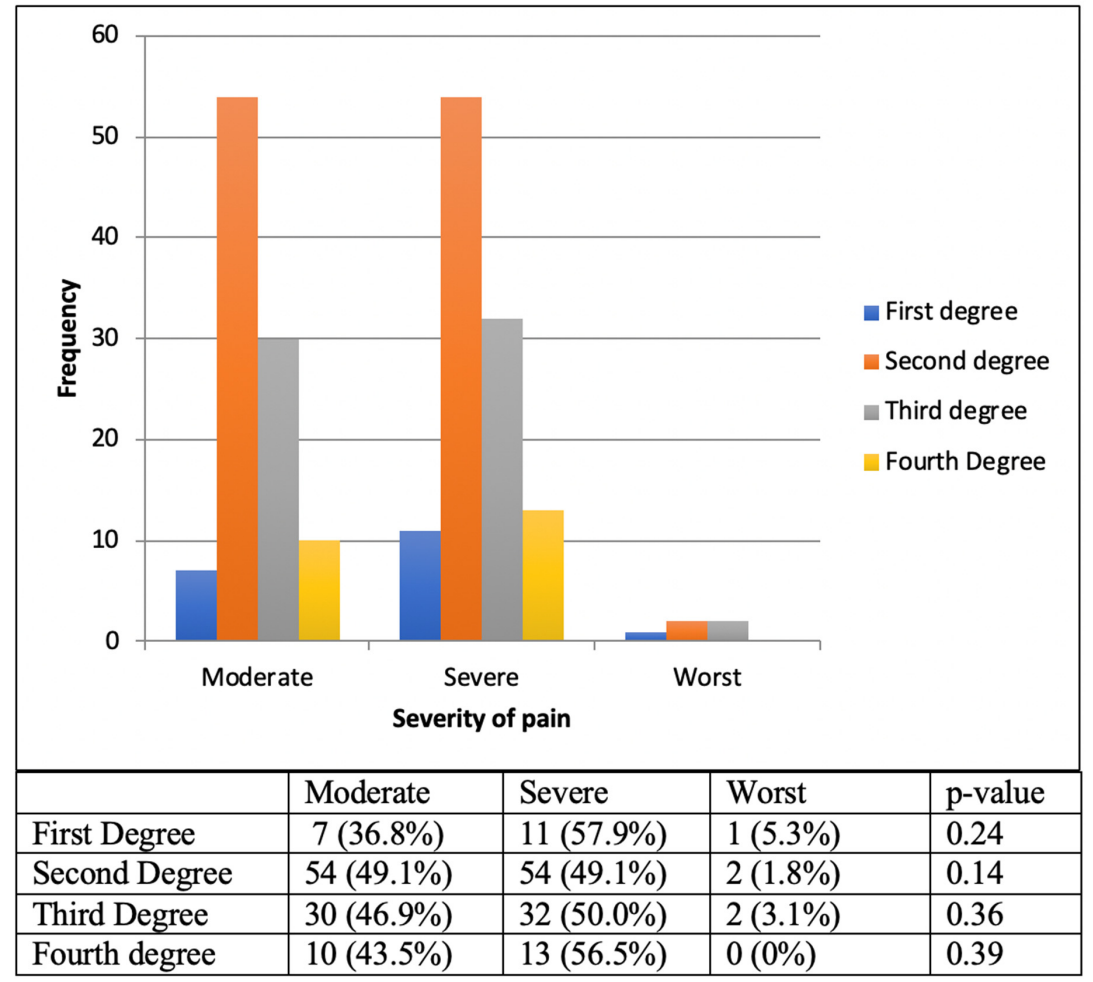

Figure 4. Relationship between depth of burn and VAS. 
In the ED, the majority of the patients received analgesics. To elaborate on this, all patients with major burns received analgesics except a few with minor burns, $3(6.3 \%)$. The preferred mode of analgesia at ED was unimodal, 102 (76.7\%) (Refer to Table 2).

Table 2. Severity of burns and modality of analgesics offered at the ED.

\begin{tabular}{cccc}
\hline \multirow{2}{*}{ Severity of Burns TBSA } & \multicolumn{2}{c}{ Analgesia Offered } & \multirow{2}{*}{ Total } \\
\cline { 2 - 3 } & Multimodal & Unimodal & \\
\hline Minor & $5(11.1 \%)$ & $40(88.9 \%)$ & $45(100 \%)$ \\
Moderate & $6(12.8 \%)$ & $41(87.2 \%)$ & $47(100 \%)$ \\
Major & $20(48.8 \%)$ & $21(51.2 \%)$ & $41(100 \%)$ \\
Total & $31(23.3 \%)$ & $102(76.7 \%)$ & $133(100 \%)$ \\
\hline
\end{tabular}

Analgesics were used in the ED, and most of the burn victims were offered opioids. Morphine was the most preferred opioid, 54 (50\%), and the intravenous route was the most preferred route of administration (refer to Table 3).

Table 3. Choice of analgesics utilized in relation to severity of burns.

\begin{tabular}{|c|c|c|c|c|c|}
\hline \multirow{3}{*}{$\begin{array}{c}\text { Type of Analgesics } \\
\text { Used }\end{array}$} & \multirow{2}{*}{\multicolumn{3}{|c|}{ Burn Severity }} & \multicolumn{2}{|c|}{ Route of Administration } \\
\hline & & & & \multirow[t]{2}{*}{ Intravenous } & \multirow[t]{2}{*}{ Intramuscular } \\
\hline & Minor & Moderate & Major & & \\
\hline Opioids (108) & $29(26.9 \%)$ & $40(37 \%)$ & $39(36.1 \%)$ & & \\
\hline Morphine $(n=54)$ & $7(13 \%)$ & $20(37 \%)$ & $27(50 \%)$ & $28(51.2)$ & $26(50.8)$ \\
\hline Pethidine $(n=9)$ & $2(22.2 \%)$ & $4(44.4 \%)$ & $3(33.2 \%)$ & $3(33.3 \%)$ & $6(66.7 \%)$ \\
\hline Tramadol $(n=45)$ & $20(44.4 \%)$ & $16(31 \%)$ & $9(20 \%)$ & $41(91.1 \%)$ & $4(8.9 \%)$ \\
\hline Diclofenac $(n=24)$ & $7(29.2 \%)$ & $5(20.8 \%)$ & $12(50 \%)$ & 0 & $24(100 \%)$ \\
\hline Paracetamol $(n=35)$ & $15(42.9 \%)$ & $8(22.8 \%)$ & $12(34.3 \%)$ & $26(74 \%)$ & $*$ \\
\hline
\end{tabular}

\section{Discussion}

Few studies within the region have been done to address the subject of pain control in patients suffering from burns. No study has investigated the aspect of pain assessment and its control within the African subcontinent.

The present study reports a male to female ratio of 1.8:1. Three studies from Kenya reported similar findings $[7,20]$. Median age of participants in this study was 28 years with an IQR of 22-34 years. Other studies within the region showed a contrasting age distribution where most of their sample were children. A study from Eldoret [7] had a mean age of 10. In contrast, another study from Kijabe [5] showed a mean age of 8 years, while in Tanzania a study reported a mean age of 3 years [21]. In Kenya, the incidence of burns is 3\% [3] and 90\% of these burns are thermal in etiology [6,7]. This study shows that among patients with thermal burns admitted to $\mathrm{KNH}$, the majority were due to open flame and scald each accounting for 35.5\% of enrolled participants. Another study from Tanzania showed a $56 \%$ prevalence of scald rather than flame burn in $40 \%$ of their sample [21]. This could be attributed to the age of the participants, since scald burns are usually a common occurrence in the pediatric population, while in this study most of the participants were adults.

There was a similar distribution of participants in terms of burns severity, minor burn (34.8\%), moderate burn (35.5\%) and severe burns (29.7\%). The median TBSA was 19.5\% (IQR 15-27.5\%), our patients had a slightly higher TBSA compared to a previous study by the same institution from 2005, which reported a mean TBSA of 17\% [20].

This study shows that pain assessment is hardly performed by ED staff, with a meager $2 \%$ of participants having their pain assessed. The pain assessment tools used were FPRS $(67 \%)$ and VAS (33\%). Pain assessment was lower perhaps due to few trained staff who could perform pain assessment in the emergency department, also awareness of pain 
management in burns has been slacking. Tools for pain assessment have been lacking in the ED, hence limiting this assessment even further. In our study, the pain assessment figures are negligible, yet it is known that objective pain assessment is very important to guide a physician in prescribing the correct analgesic to have a pain-free state [22,23]. We assessed pain in every participant, and the mean VAS score was 7 (SD 1.4). There was no statistical association between burn severity in TBSA and VAS in this study. A review article from Greece stated that acute burns are more painful in major burns [11]. Many authors have studied the effects of poorly managed pain worldwide and locally; they describe effects such as delayed healing, psychological disturbances and chronic pain $[6,12,19]$. The presence of pain has been shown to prolong the hyperactive state, which affects healing due to the catabolic nature of this response. Mitigation of pain as a factor is within the capacity of a medical team by appropriate management of pain [9,24-26].

At the ED, 96\% of the participants had some sort of analgesia offered. The mode of offering analgesia was mainly unimodal, 76\%. All participants who had major burns received analgesia. A study on pain management recommends the utility of multimodal pharmacologic pain management from the point of contact with a major burn patient. Our findings are contrary to this study from the United States. In the KNH emergency department, the choice of analgesic was mainly opioids, $78 \%$, the opioid of choice was morphine in $50 \%$, and the preferred route of opioid administration was intravenous in $50 \%$. This is a good practice when compared to a study from the United States, which agrees on the utility of opioids as the backbone of pain management in burn victims [17]. A key difference was that this paper suggested utility of an opioid with a NSAID, or acetaminophen or an anxiolytic. The utility of opioids and route of administration from this study follows recommendations of burn pain management; however, it should be used in conjunction with other medications $[12,26]$. The results of our study differ from other studies, which suggest the use of multimodal analgesia [12,26].

\section{Conclusions}

To conclude, $65 \%$ of burn victims sustained moderate to major burns and minority of the patients had any sort of pain assessment done at the emergency department, and as a result, burn pain was inappropriately managed. There is an urgent need to improve the assessment of burn pain treatment by scoring and therefore improving its management by involving burn surgeons and pain therapists. These specialists could insist that clinicians in the ED should assess pain in burn victims and guide them in utilizing multimodal pain management at the ED. Further studies need to be performed to understand the reasons to the ongoing practices in pain management.

\section{Limitations}

Racial differences in pain perception could have been overlooked in this study. Some patients would have taken analgesics prior to or while enroute to hospital, but this information was not captured.

What is already known on this topic:

1. Burn in jury is common and in adults, the common age group is 22-34.

2. Burn injury is associated with severe pain; this entity needs to be assessed to treat appropriately.

3. Validated pain assessment tools are available for easy use.

What this study adds:

1. Pain management is not forgotten, but it could be better managed if it was assessed.

2. All front-liners receiving burn victims needs to evaluate pain.

3. All healthcare workers need to be taught how to assess the pain.

4. Shows a gap in the assessment of pain and treatment of pain. 
Author Contributions: Conceptualization, V.R.K., N.E.O. and F.N.; data collection, V.R.K.; data analysis and review, V.R.K., N.E.O. and F.N.; writing-review and editing, V.R.K., N.E.O. and F.N. All authors have read and agreed to the published version of the manuscript.

Funding: This research was funded by the department of Research of Kenyatta National Hospital.

Institutional Review Board Statement: Ethical approval to carry out this study was sought from $\mathrm{KNH} / \mathrm{UoN}$ Ethics and Research Committee. The study was conducted according to the guidelines of the Declaration of Helsinki, and approved by Kenyatta National Hospital/University of Nairobi Ethics \& Research Committee. Protocol approval Number P/635//10/2014.

Informed Consent Statement: Informed consent was obtained from all subjects involved in the study.

Data Availability Statement: The data were captured on a data collection form and then entered on an electronic version of the form using Epidata. This was then converted to a data file, which was used for data analysis. The data set file is available for review as and when needed.

Acknowledgments: I would like to thank all colleagues in the Emergency Department of Kenyatta National Hospital. We would like to thank John Kinuthia, from the Research and Programs office, KNH for funding this study.

Conflicts of Interest: The authors declare no conflict of interest.

\section{References}

1. Peck, M.D. Epidemiology of burns throughout the world. Part I: Distribution and risk factors. Burns 2011, 37, 1087-1100. [CrossRef] [PubMed]

2. WHO. The Global Burden of Disease: 2004 Update; World Health Organization: Geneva, Switzerland, 2008.

3. Odero, W.O.; Kibosia, J.C. Incidence and characteristics of injuries in Eldoret, Kenya. East Afr. Med. J. 1995, 72, 706-710. [PubMed]

4. Mzezewa, S.; Jonsson, K.; Aberg, M.; Salemark, L. A Prospective study on the epidemiology of burns in patients admitted to the Harare burn units. Burns 1999, 25, 499-504. [CrossRef]

5. Chalya, P.L.; Mabula, J.B.; Dass, R.M.; Giiti, G.; Chandika, A.B.; Kanumba, E.S.; Gilyoma, J.M. Pattern of childhood burn injuries and their management outcome at Bugando Medical Centre in Northwestern Tanzania. BMC Res. Notes 2011, 4, 485. [CrossRef]

6. Nthumba, P.M. Outcome of Moderate and Severe Thermal Injuries at Kenyatta National Hospital. Master's Thesis, Department of Surgery, University of Nairobi, Nairobi, Kenya, 2002.

7. Lelei, L.; Chebor, A.; Mwangi, H. Burns injuries among in-patients at Moi Teaching and Referral Hospital, Eldoret, Kenya. Ann. Afr. Surg. 2011, 8, 12-15.

8. Orgill, D.P. Excision and skin grafting of thermal burns. N. Engl. J. Med. 2009, 360, 893-901. [CrossRef]

9. Richardson, P.; Mustard, L. The management of pain in the burns unit. Burns 2009, 35, 921-936. [CrossRef]

10. American Pain Society. The assessment and management of acute pain in infants, children, and adolescents. Pediatrics 2001, 108, 793-797. [CrossRef]

11. Summer, G.J.; Puntillo, K.A.; Miaskowski, C.; Green, P.G.; Levine, J.D. Burn injury pain: The continuing challenge. J. Pain 2007, 8, 533-548. [CrossRef]

12. Hammond, J.; Ward, C. Burns in octogenarians. South Med. J. 1991, 84, 1316-1319. [CrossRef]

13. Mahar, P.D.; Wasiak, J.; O'Loughlin, C.J.; Christelis, N.; Arnold, C.A.; Spinks, A.B.; Danilla, S. Frequency and use of pain assessment tools implemented irandomiseded controlled trials in the adult burns population: A systematic review. Burns 2012, 38, 147-154. [CrossRef] [PubMed]

14. Gordon, M.; Greenfield, E.; Marvin, J.; Hester, C.; Lauterbach, S. Use of Pain Assessment Tool: Is There a Preference? J. Burn Care Rehabil. 1998, 19, 451-454. [CrossRef] [PubMed]

15. Frampton, C.L.; Hughes-Webb, P. The measurement of pain. Clin. Oncol. 2011, 23, 381-386. [CrossRef]

16. Malenfant, A.; Forget, R.; Papillon, J.; Amsel, R.; Frigon, J.Y.; Choinière, M. Prevalence and characteristics of chronic sensory problems in burn patients. Pain 1996, 67, 493-500. [CrossRef]

17. Macharia, L.M. The Prevalence of Depression among Patients with Burns. Ph.D. Thesis, University Nairobi Dept Psychiatry, Nairobi, Kenya, 2013.

18. Dale, E.L.; Mueller, M.A.; Wang, L.; Fogerty, M.D.; Guy, J.S.; Nthumba, P.M. Epidemiology of operative burns at Kijabe Hospital from 2006 to 2010, pilot study of a web-based tool for creation of the Kenya Burn Repository. Burns 2013, 39, 788-795. [CrossRef]

19. Nthumba, P.M.; Oliech, J.S. Outcome of moderate and severe thermal injuries at Kenyatta National Hospital. East Cent. Afr. J. Surg. 2005, 10, 37-42.

20. Ulmer, J.F. Burn pain management: A guideline-based approach. J. Burn Care Rehabil. 1998, 19, 151-159. [CrossRef]

21. Gallagher, G.; Rae, C.P.; Kinsella, J. Treatment of pain in severe burns. Am. J. Clin. Dermatol. 2000, 1, 329-335. [CrossRef]

22. Castana, O.; Anagiotos, G.; Rempelos, G.; Adalopoulou, A.; Kokkinakis, C.; Giannakidou, M.; Diplas, D.B.; Alexakis, D. Pain response and pain control in burn patients. Ann. Burns Fire Disasters 2009, 22, 88-89.

23. de Castro, R.J.A.; Leal, P.C.; Sakata, R.K. Pain management in burn patients. Braz. J. Anesthesiol. 2013, 63, 149-153. [CrossRef] 
24. Byers, J.F.; Bridges, S.; Kijek, J.; LaBorde, P. Burn patients' pain and anxiety experiences. J. Burn Care Rehabil. 2001, 22, 144-149. [CrossRef] [PubMed]

25. Kehlet, H. Surgical Stress: The Role of Pain and Analgesia. Br. J. Anaesth. 1989, 63, 189-195. [CrossRef] [PubMed]

26. Patterson, D.R.; Hoflund, H.; Espey, K.; Sharar, S.R. Pain Management. In Bonica's Management of Pain, 3rd ed.; Loeser, J., Ed.; Lippincot, Williams \& Wilkins: Philadephia, PA, USA, 2001. 